\title{
In vitro synergistic potentials of novel antibacterial combination therapies against Salmonella Typhimurium, Escherichia coli and Staphylococcus aureus
}

Md Akil Hossain ( $\square$ mdakil_hossain@yahoo.com)

Animal and Plant Quarantine Agency https://orcid.org/0000-0001-7131-4814

Hae-Chul Park

Animal and Plant Quarantine Agency

Kwang-jick Lee

Animal and Plant Quarantine Agency

\section{Sung-Won Park}

Animal and Plant Quarantine Agency

\section{Seung-Chun Park}

Kyungpook National University

\section{JeongWoo Kang}

Animal and Plant Quarantine Agency

\section{Research article}

Keywords: Combination therapy, critically important antibiotics, Phenolic compounds, gallic acid, hamamelitannin, biofilm

Posted Date: May 7th, 2019

DOI: https://doi.org/10.21203/rs.2.9511/v1

License: (c) (i) This work is licensed under a Creative Commons Attribution 4.0 International License. Read Full License

Version of Record: A version of this preprint was published at BMC Microbiology on May 14th, 2020. See the published version at https://doi.org/10.1186/s12866-020-01810-x. 


\section{Abstract}

Background: Bacteria have remarkable abilities to acquire resistance against antibiotics by several mechanisms. New strategies are needed to block the development of resistance and to prolong the life of traditional antibiotics. This study aimed to increase the efficacy of existing antibiotics by combining them with the opportunistic phenolic compound gallic acid (GA) and its derivatives. Fractional inhibitory concentration (FIC) indexes of phenolic compound-antibiotic combinations against Salmonella enterica serovar Typhimurium, Escherichia coli and Staphylococcus aureus were determined. Based on the FIC indexes and clinical importance, 3 combinations were selected to evaluate their effects on the virulence factors of these bacteria. The in vitro cytotoxicity of GA and hamamelitannin in the Rattus norvegicus (IEC6) cell line were evaluated. Results: Phenolic compounds demonstrated considerable antibacterial effects as the minimum inhibitory concentrations (MICs) of epigallocatechin, GA and hamamelitannin found against different strains were (32-1024), (128-1024) and (512- $\geq 2048) \mu \mathrm{g} / \mathrm{mL}$, respectively. The FIC indexes of the combined antibacterials against these strains were $0.281-1.016$. The ultrastructural morphology and time-kill assays showed that the GAceftiofur combination, and hamamelitannin-erythromycin and GA-ampicillin combinations more efficiently inhibited the growth of S. Typhimurium and E. coli, respectively, compared to the individual antibiotics. Biofilm viability and the swimming and swarming motilities of S. Typhimurium in the presence of GA-ceftiofur and $\mathrm{E}$. coli in the presence of the hamamelitannin-erythromycin and GA-ampicillin combinations were more competently inhibited than individual antimicrobials. The $50 \%$ inhibitory concentrations (IC50) of GA and hamamelitannin in IEC- 6 cells were $564.55 \mu \mathrm{M}$ and $988.54 \mu \mathrm{M}$, respectively. Conclusions: The phenolic compounds increase the efficacy of existing antibiotics might be by disrupting virulence factors. We can conclude that these antibacterial combinations are safe and can be potential medications to treat S. Typhimurium, E. coli and S. aureus infections in animals and humans. Further study to confirm this effect in in vivo system and to determine the precise mechanism of action should be undertaken to establish these combinations as medications.

\section{Background}

Infectious diseases are the third most significant cause of mortality around the world according to the World Health Organization (WHO) [1]. Multidrug-resistant (MDR) bacteria are one of several vital aetiologic agents contributing to the emergence of infections [2]. The rapid emergence of resistant bacteria is occurring worldwide, endangering the efficacy of antibiotics [3-8]. The antibiotic resistance crisis has been attributed to the overuse and misuse of these medications, as well as a lack of new drug development by the pharmaceutical industry due to reduced economic incentives and challenging regulatory requirements $[4-7,9-16]$. The Centers for Disease Control and Prevention (CDC) has classified a number of bacteria as presenting urgent, serious, and concerning threats, many of which are already responsible for placing substantial clinical and financial burden on the health care system, patients, and their families $[3,7,12,17]$.

The frequency of resistance is observed equally among Gram-negative and Gram-positive organisms, although Gramnegative bacteria are more prone to develop the MDR phenotype [2]. Together with other bacterial species, Escherichia coli, Salmonella Typhimurium and Staphylococcus aureus are severely antibiotic-resistant and were recently enlisted and designated as priority class bacterial pathogens in urgent need of effective antibiotics by the WHO [18]. The gravity of the situation is highlighted by the fact that clinical isolates of these species have up to 1000 -fold higher $50 \%$ growth inhibition concentrations $\left(\mathrm{GIC}_{50}\right)$ for a range of antibiotics with different mechanisms of action relative to the sensitive/resistant breakpoints recommended by the Clinical and Laboratory Standard Institute (CLSI). These trends show the urgent need for the development of new antimicrobials that can treat or potentiate current antibiotics against MDR bacteria [19]. The scientific community is continuously searching for new classes of disinfection systems that could act efficiently against these pathogens [20]. Certain naturally occurring phenolic compounds have antioxidant, anticarcinogenic, and antimicrobial activities [21, 22]. 
The phenolic compound (methyl gallate and pyrogallol)-containing Nymphaea tetragona 50\% methanol extract (NTME) was found to have quorum sensing and virulence factor inhibitory effects [23]. The synergistic antibacterial and quorum sensing (QS) inhibition effects of the phenolic compound-containing NTME were also evident in our earlier study [24]. The phenolic compound gallic acid demonstrated the potential to inhibit $S$. mutans biofilms [25]. Recently, we also reported that methyl gallate, a gallic acid derivative, can efficiently interfere with the QS regulatory pathways of $P$. aeruginosa and inhibit the adhesion, invasion and intracellular survival of $S$. Typhimurium [26, 27]. These properties of bacterial are known to have a significant role in increasing pathogenicity and antimicrobial resistance [28].

Gallic acid derivatives contain a large number of hydroxyls, which can form protonic and ionic bonds and combine with many biological proteins, such as enzymes, carriers, ion channels and receptors, deactivating them and consequently exhibiting bacterial inhibition. Additionally, many phenols can non-specifically affect microorganism molecular targets [29]. These observations initiate the speculation that gallic acid derivatives may also potentiate the efficacy of existing antibiotics. Thus, we intended to evaluate the synergistic antibacterial potentials of gallic acid and its 4 derivatives in this study with 8 currently available antibiotics against E. coli, S. Typhimurium and S. aureus. Additionally, the effects of those combination antibacterials against selected virulence factors, including biofilm formation and motility, were determined. Finally, in vitro cytotoxicity tests of potent phenolic compounds were conducted to determine the safety profile of these compounds for further commercial use.

\section{Materials And Methods}

\section{Chemicals, Reagents and Bacterial Strains}

Unless otherwise mentioned, all the chemicals, reagents and media were from Sigma-Aldrich (St. Louis, MO, United States). Quality control strains of E. coli (ATCC 25922), S. aureus (ATCC 25923) and S. Typhimurium (ATCC 14028) and clinical strains of S. Typhimurium (V08-S-HA-06-170, V15-S-HA-02-210, SAL 109, SAL 202 and SAL 224) were used in this study. Clinical strains used in this study were obtained from farms of different regions in the Republic of Korea. All the strains were incubated in Mueller Hinton broth (MHB; Becton Dickinson and Company, Becton Drive, NJ, United States) for $20 \mathrm{~h}$ in a rotating incubator at $200 \mathrm{rpm}$ and $37^{\circ} \mathrm{C}$.

Minimum Inhibition Concentrations of Antibacterial Agents

MICs were determined by the standard broth microdilution method according to the CLSI guidelines [30] in cationadjusted (CA)-MHB using an inoculum concentration of $\sim 5 \times 10^{5} \mathrm{CFU} / \mathrm{mL}$. Different antibacterial solutions were serially diluted in 96-well plates in $100 \mu \mathrm{L}$ volumes. The cultures of different bacterial strains were diluted to adjust 0.5 McFarland units and, again diluted 100-times. Hundred microliters of these diluted bacterial suspensions were dispensed to all the wells of 96 -well plates which contain $100 \mu \mathrm{L}$ of antibiotic solution. After incubation at $35^{\circ} \mathrm{C}$ overnight, the turbidity in each well was checked. The lowest concentrations of the antibacterial that completely inhibited any increase in turbidity were considered as the MICs.

Fractional Inhibition Concentration (FIC) Index of Antibacterial Agents

A slightly modified version of the previously described checkerboard microdilution method was utilized to determine the combination interactions of the commercial antibiotics and phenolic compounds [31]. One antibacterial was vertically diluted and the other antibacterial was horizontally diluted in 96-well plates to achieve a matrix of different combinations of the 2 antibacterials. Similar dilutions of individual drugs and the drug-free medium control were included in each test plate. Bacterial cultures in early log phase were diluted and $100 \mu \mathrm{L}$ of the diluted bacterial suspension was added to each well of the 96-well plates, where the final inoculum concentration after transferring to each well would be $\sim 5 \times 10^{5}$ $\mathrm{CFU} / \mathrm{mL}$. Plated bacteria were incubated at $35^{\circ} \mathrm{C}$ for 16 to $20 \mathrm{~h}$. The fractional inhibitory concentration (FIC) and the FIC 
index (FICl) were calculated from the MICs of the drugs alone and in combination. The FIC is the MIC of a drug in presence of another drug divided by the MIC of the individual drug, and the FICl is the sum of the FICs of the individual drugs. An $\mathrm{FICl}$ of $\leq 0.5$ is regarded as synergistic, $0.5<\mathrm{FICl} \leq 1$ is considered additive, $1<\mathrm{FICl} \leq 2$ is considered indifferent, and an $\mathrm{FICl}>2$ is considered antagonistic effects [32].

Effect of Antibacterial Combinations on Bacterial Inhibition Rates

The time-dependent inhibition effects of gallic acid-ceftiofur against $S$. Typhimurium and hamamelitannin-erythromycin and gallic acid-ampicillin against E. coli were evaluated according to a previously reported method [24]. Drug compounds alone and in combination were supplemented in $10 \mathrm{~mL}$ MHB broth in $15 \mathrm{~mL}$ falcon tubes. Bacterial cultures in early log phase were diluted and then resuspended in the drug-supplemented broth to a final inoculum concentration of $5 \times 10^{6} \mathrm{CFU} / \mathrm{mL}$. A tube containing $5 \times 10^{6} \mathrm{CFU} / \mathrm{mL}$ of bacteria in $10 \mathrm{~mL}$ MHB without any drug was used as a control. The samples were incubated at $37^{\circ} \mathrm{C}$ at $200 \mathrm{rpm}$ in a shaking incubator. At different time points $(0,1,2,3,4,6,8$, 12 , and $24 \mathrm{~h}) 100 \mu \mathrm{L}$ of the cultures were collected from all tubes and serially diluted 10 -fold in agar saline. Aliquots of the 10-fold dilutions $(20 \mu \mathrm{L})$ were spread on Mueller Hinton agar (MHA) plates and incubated overnight at $37^{\circ} \mathrm{C}$. The CFUs of the cultures were determined by counting the number of colonies from each dilution. The mean $\log { }^{10} \mathrm{CFU} / \mathrm{mL}$ for each compound was plotted against different times.

Effect of Antibacterial Combinations on Bacterial Cell Morphology

The effects of the gallic acid-ceftiofur combination on the morphology of $S$. Typhimurium and the hamamelitanninerythromycin and gallic acid-ampicillin combinations on the morphology of $E$. coli cells were evaluated. Drug compounds alone or in combination were supplemented into $10 \mathrm{~mL}$ of MHB broth in $15 \mathrm{~mL}$ falcon tubes. Bacterial cultures in early log phase were diluted and then resuspended in the drug-supplemented broth to a final inoculum concentration of $5 \times 10^{6} \mathrm{CFU} / \mathrm{mL}$. A tube containing $5 \times 10^{6} \mathrm{CFU} / \mathrm{mL}$ of bacteria in $10 \mathrm{~mL} \mathrm{MHB}$ without any drug was used as a control. The bacteria in tubes were incubated overnight at $37^{\circ} \mathrm{C}$ and $200 \mathrm{rpm}$ in a shaking incubator. Then, the cells were harvested, washed, and dehydrated according to a previously reported protocol [33]. The ultrastructural morphology of treated $S$. Typhimurium and E. coli cells was studied using a scanning electronic microscope (SEM; models S-4300 and EDX-350; Hitachi, Japan).

Effect of Phenolic Compounds on Quorum Sensing (QS) Inhibition

The potentials of QS inhibition of phenolic compounds were verified in accordance with the method described by Alvarez et al. [34]. The standard disk diffusion assay using the biomonitor $C$. violaceum strain (ATCC 12472) was performed for this evaluation. C. violaceum ATCC 12472 was dispensed onto molten Luria-Bertani (LB, Becton Dickinson and Company, Becton Drive, NJ, United States) agar medium in a $(90 \times 15 \mathrm{~mm})$ petri dish as to make the bacterial density $5 \times$ $10^{6} \mathrm{CFU} / \mathrm{mL}$. Sixty microliter solutions of antibiotics that contain $60 \mu \mathrm{g}$ of each compound were loaded onto sterile paper disks, and then the drug-containing paper disks were allowed to air dry and placed on the solidified agar. The bacteria on the agar plates were incubated overnight at $30^{\circ} \mathrm{C}$ and examined for violacein production. QS inhibition was determined by the presence of a colourless, opaque, but viable halo around the disks.

Effect of Antibacterial Combinations on Biofilm Growth and Viability

The inhibitory effect of combination antibacterials on biofilm formation was determined using a slightly modified version of a previously reported spectrophotometric method [ 35,36 ]. Briefly, test compounds were supplemented into trypticase soy broth (TSB; Becton Dickinson and Company, Becton Drive, NJ, United States ) in three separate wells of a 96-well microplate for each concentration. The final concentrations of the test compounds alone or in combination (gallic acid-ceftiofur, gallic acid-ampicillin and hamamelitannin-erythromycin ) were $1 / 4 \mathrm{MIC}, 1 \frac{1}{2} \mathrm{MIC}$ and $1 \mathrm{MIC}$ after 
bacterial inoculation. Cultures of $S$. Typhimurium and $E$. coli were incubated for $18 \mathrm{~h}$ in a rotating incubator at $200 \mathrm{rpm}$ and $37^{\circ} \mathrm{C}$. The bacterial cultures were diluted in TSB, and then $100 \mu \mathrm{L}$ of the diluted cultures were added to the designated wells to a final cell density of $1 \times 10^{6} \mathrm{CFU} / \mathrm{mL}$ after inoculation. The optical densities of the bacteria in the wells of a 96-well plate were measured at $600 \mathrm{~nm}$ instantly after inoculating bacteria. The bacteria in the 96-well plate with drugs were incubated for $24 \mathrm{~h}$ at $37^{\circ} \mathrm{C}$, and after incubation, the optical densities were again measured to determine the growth of planktonic cells. Then the supernatants from the wells of a 96-well plate were discarded carefully without affecting the biofilms which are attached on the well-surfaces. The adherent media and drug components were removed by washing the wells three-times with sterile phosphate buffer saline (PBS, pH 7.2). Then, $200 \mu \mathrm{L}$ of methanol (99\%, v/v) were dispensed to the wells, and kept for $20 \mathrm{~min}$ to fix the biofilms. The biofilms were then stained by introducing $100 \mu \mathrm{L}$ of crystal violet $(0.2 \%, \mathrm{w} / \mathrm{v})$ solution to the wells and keeping at room temperature for $15 \mathrm{~min}$. The excess or unbound crystal violet in the wells was removed by four-times washing with PBS. The crystal violet on the biofilm cells was extracted in $100 \mu \mathrm{L}$ of $95 \%$ ethanol, and their optical densities (OD) were measured, which yields a measure of biofilm formation (compared to the control). Measurements were performed in triplicate and repeated 3 times.

Previously, reported biofilm viability assay methods were utilized to evaluate the effects of combination drugs on the viability of the biofilms produced by $S$. Typhimurium and E. coli $[23,37]$. In brief, sterile TSB broth of $2 \mathrm{~mL}$ were transferred to a Nunc ${ }^{\text {TM }}$ Lab-Tek $^{\text {TM }}$ II Chambered Cover glass (ThermoFisher Scientific, Waltham, MA, United States ) and diluted cultures of $S$. Typhimurium and $E$. coli were inoculated into the broth to a final concentration of $1 \times 10^{6} \mathrm{CFU} / \mathrm{mL}$. The Nunc ${ }^{T M}$ Lab-Tek $^{T M}$ II Chambered Cover glass which contain S. Typhimurium and E. coli cells were kept in a static incubator at $37^{\circ} \mathrm{C}$ until $48 \mathrm{~h}$ for biofilm formation. Every $24 \mathrm{~h}$, the TSB broth used in biofilm formation was replaced by fresh, sterile TSB broth. The supernatants and planktonic cells were discarded after incubating the bacteria for $48 \mathrm{~h}$, and the chambered cover glasses were washed by $1 \times$ PBS. Then, $2 \mathrm{~mL}$ of sterile TSB containing the test compounds alone or in combination (gallic acid-ceftiofur, gallic acid-ampicillin and hamamelitannin-erythromycin ) at $1 / 4 \mathrm{MIC}, 1 / 2 \mathrm{MIC}$ and $1 \mathrm{MIC}$ concentrations were added. The biofilms were again kept in a static incubator at $37^{\circ} \mathrm{C}$ for $24 \mathrm{~h}$ to treat the developedbiofilm cells. After $24 \mathrm{~h}$ of exposure to the test compounds, the biofilms were again washed with sterile double distilled water (DDW) and stained with BacLight live/dead stain (ThermoFisher Scientific, Waltham, MA, United States ). Confocal laser scanning microscope (CLSM) was used to scan the viable and nonviable biofilms. Imaging was performed with a Zeiss LSM 700 CLSM (Zeiss, Oberkochen, Germany ) within the $488 \mathrm{~nm}$ excitation and $560-600 \mathrm{~nm}$ emission range. Zen 2009 software was used to execute image acquisition as well as subsequent image manipulation. Untreated biofilm was used as a control.

Effect of Antibacterial Combinations on the Motility of Bacterial Cells

The swarming and swimming motilities of E. coli (ATCC 25922) and S. Typhimurium (ATCC 14028) in the presence of the combination drugs were evaluated according to previously published methods with slight modifications [38, 39]. The media used for the E. coli (ATCC 25922) swarming assay was composed of 0.8\% Luria-Bertani (Becton Dickinson and Company, Becton Drive, NJ, United States) supplemented with $0.5 \%$ glucose (Scharlab, Barcelona, Spain) and $0.6 \%$ agar (Becton Dickinson and Company, Becton Drive, NJ, United States). Nutrient broth (NB; Becton Dickinson and Company, Becton Drive, NJ, United States) supplemented with $0.5 \%$ glucose and $0.5 \%$ agar was used for the evaluation of $S$. Typhimurium (ATCC 14028) swarming motility. The media used to evaluate $E$. coli swimming activity was composed of $1 \%$ tryptone broth supplemented with $0.5 \% \mathrm{NaCl}$ (Scharlab, Barcelona, Spain) and $0.3 \%$ agar. Nutrient broth supplemented with $0.5 \%$ glucose and $0.25 \%$ agar was used as the media for the $S$. Typhimuriumswimming motility assay. Molten agar plates were supplemented with $1 / 4 \mathrm{MIC}, 1 \frac{1}{2} \mathrm{MIC}$ and $1 \mathrm{MIC}$ concentrations of test compounds alone or in combination (gallic acid-ceftiofur, gallic acid-ampicillin and hamamelitannin-erythromycin ). A non-supplemented drug free plate was employed as the negative control. The plates were allowed to dry for $1 \mathrm{~h}$ and then $2 \mu \mathrm{L}$ of $E$. coli and $S$. Typhimurium cultures were inoculated onto the respective swarming and swimming agar plates. For both strains, swarm plates were kept at $37^{\circ} \mathrm{C}$ overnight, whereas swim plates were incubated at $37^{\circ} \mathrm{C}$ for $10 \mathrm{~h}$. After incubation, the swarm

Page 5/23 
and swim zone diameters were measured using calibrated digital slide callipers (Mitotoyo, Japan), and photographs of the plates were captured.

Cell Viability in the Presence of Antibacterial Agents

The in vitro viability of a small intestine cell line of Rattus norvegicus (IEC-6; American Type Culture Collection CRL-1592, VA, United States) in the presence of combination drugs were evaluated according to standard EZ-cytox (EZ-1000; Daeillab Service Co. Ltd., Jeonju, South Korea) assay method. In brief, the IEC- 6 cells were cultured at $37^{\circ} \mathrm{C}$ under a humidified atmosphere of $5 \%$ carbon dioxide $\left(\mathrm{CO}_{2}\right)$ in Dulbecco's Modified Eagle's medium (DMEM; ThermoFisher Scientific, Waltham, MA, United States) with 4 mM L-glutamine ( ThermoFisher Scientific, Waltham, MA, United States), adjusted to contain $1.5 \mathrm{~g} / \mathrm{L}$ sodium bicarbonate (Carolina Biological Supply Company, Burlington, NC, United States) and $4.5 \mathrm{~g} / \mathrm{L}$ glucose and supplemented with $0.1 \mathrm{Unit} / \mathrm{mL}$ bovine insulin (90\%) and foetal bovine serum (10\%). The cells were subpassaged at a ratio of 1:5 twice a week. One hundred microliters of suspended cells $\left(2 \times 10^{4} \mathrm{cells} / \mathrm{mL}\right.$ in the abovementioned DMEM medium) were acclimated in 96 -well plates at $37^{\circ} \mathrm{C}$ under $5 \% \mathrm{CO}_{2}$ for $24 \mathrm{~h}$. The medium from each well was aspirated and the cells were washed twice. One hundred microliters of the test compounds at various concentrations in the abovementioned DMEM medium were dispensed into each well and the cells in the drugsupplemented medium were allowed to incubate at $37^{\circ} \mathrm{C}$ under $5 \% \mathrm{CO}_{2}$ for $24 \mathrm{~h}$. A total of $10 \mu \mathrm{L}$ of EZ-cytox were added to each well. After incubation for $2 \mathrm{~h}$, the absorbances in each well were measured at $450 \mathrm{~nm}$ using a plate reader. Cells not treated with any drugs were assigned as the control. The cell viability (\%) was calculated by the following formula:

Cell viability $(\%)=(O D$ of drug-treated sample/OD of untreated sample $) \times 100$, where OD is the optical density [40].

Statistical Analysis

Results are presented as the means \pm standard deviation (SD) of triplicate analysis. Statistical analysis was carried out by using SAS software (SAS Institute Inc., Cary, NC, USA). One-way analysis of variance (ANOVA) followed by F-test was used to compare the results. Statistical significance was considered when the $P$-value was $<0.05$.

\section{Results}

Antibacterial Activities of Commercial Antibiotics and Phenolic Compounds

Antibacterial activities of different antibiotics and phenolic compounds were evaluated against quality control (QC) strains of E. coli, S. aureus, S. Typhimurium and clinical strains of $S$. Typhimurium. The MICs of the different antibiotics (amoxicillin, ampicillin, cefotaxime, ceftiofur, erythromycin, florfenicol, marbofloxacin, norfloxacin, penicillin $\mathrm{G}$ and Theamphenicol) against QC strains of E. coli, S. aureus and S. Typhimurium ranged from $0.125 \sim 128.00 \mu \mathrm{g} / \mathrm{mL}$, $0.125 \sim 4.00 \mu \mathrm{g} / \mathrm{mL}$ and $0.062 \sim 128.00 \mu \mathrm{g} / \mathrm{mL}$, respectively. In contrast, the MICs of the commercial antibiotics against the clinical isolates of $S$. Typhimurium ranged from 0.25 to $\geq 1024 \mu \mathrm{g} / \mathrm{mL}$. The results in Table 1 clearly demonstrate that the MICs of almost all of these commercial antibiotics against the clinical isolates were increased by several folds, which indicates that resistance has developed in these clinical strains [41-45] (Additional file 1). The MICs of phenolic compounds (epicatechin, epicatechin gallate, epigallocatechin, gallic acid and hamamelitannin) against the QC strains and clinical isolates of $S$. Typhimurium ranged from 256 to $\geq 1024 \mu \mathrm{g} / \mathrm{mL}$, with gallic acid being the most potent among all the compounds. The MICs of the phenolic compounds against the QC strains of E. coli and S. aureus ranged from $32.00 \sim 2048.00 \mu \mathrm{g} / \mathrm{mL}$.

In Vitro Synergy with Commercial Antibacterials 
Checkerboard microdilution assays were performed to evaluate the combination interactions of the commercial antibacterials with the phenolic compounds. The results of the combined activities are presented in (Additional file 2). Synergistic effects against E. coli were obtained from the combinations of thiamphenicol and gallic acid (FICl: 0.281), erythromycin and hamamelitannin (FICl: 0.375), and thiamphenicol and hamamelitannin (FICl: 0.50). The combination of erythromycin and epicatechin gallate against $S$. Typhimurium also showed synergistic antibacterial effects (FICl: 0.50 ), while none of the combinations showed synergistic effects against $S$. aureus. However, additive effects were obtained from many combinations against $S$. Typhimurium (FICl: 0.502 0.750; n=16), S. aureus (FICl: 0.504 0.625; $\mathrm{n}=13$ ) and $E$. coli (FICl: $0.502 \sim 0.625 ; \mathrm{n}=17)$. The rest of the combinations showed indifferent effects against the three bacteria, with no antagonistic effects observed from any of the combinations. Depending on both the clinical and commercial importance, 3 combinations that had synergistic or additive antibacterial effects were selected for further study.

Effects of Combination Drugs on Time- and Concentration-dependent Inhibition

The inhibitory effects of the combination antibacterials on bacterial growth rates over time are presented in Figure 1. The growth rate of $S$. Typhimurium (ATCC 14028) was approximately the same when a 1 MIC concentration of gallic acid was supplemented into the culture, and the cell density increased by approximately 1 -fold at $24 \mathrm{~h}$ compared to the density at the time of inoculation (Figure 1a). The bacterium in the presence of 1MIC ceftiofur showed complete inhibition within 8 h, after which log phase was initiated. Finally, after $24 \mathrm{~h}$, the cell density reached a level 1-fold higher than its initial density. In contrast, the cell number in the drug-free control culture increased by approximately 5 -fold within 6 h, and the same cell density was sustained out to $24 \mathrm{~h}$ of incubation. Treatment with the antibacterial combination (1MIC of both ceftiofur and gallic acid) completely inhibited the bacterial growth by $12 \mathrm{~h}$, after which time the bacteria gradually revived and finally reached a cell density at $24 \mathrm{~h}$ that was 2 -fold less than its initial 6-fold density. Sub-MIC levels of both drugs in combination prevented this increase in growth such that the final cell densities at $24 \mathrm{~h}$ were almost the same as their initial cell densities.

At $24 \mathrm{~h}$, the density of hamamelitannin (1MIC)-treated E. coli (ATCC 25922) cells was approximately 6-fold less than the drug-free control. The growth of the $E$. coli cells was also inhibited more than 6 -fold at $24 \mathrm{~h}$ in the presence of erythromycin (1MIC) compared to the control. Compared to the control, approximately 5 -fold less growth was observed after culturing this bacterium for $24 \mathrm{~h}$ with sub-MIC levels of antibacterial combinations $(1 / 2 \mathrm{MIC}$ of both hamamelitannin and erythromycin). Moreover, the $1 / 4 \mathrm{MIC}$ of both drugs together inhibited the growth by approximately 4 -fold, which demonstrated the potential of this combination drug for bacterial inhibition.

E. coli (ATCC 25922) cultures incubated with a 1 MIC concentration of gallic acid for $24 \mathrm{~h}$ showed approximately 5 -fold less growth than the drug-free control. Compared to the control, the growth of the $E$. colicells was also inhibited by approximately 6 -fold at $24 \mathrm{~h}$ in the presence of ampicillin (1MIC). Approximately 5 -fold less growth was observed compared to the control after culturing this bacterium for $24 \mathrm{~h}$ with sub-MIC levels of the antibacterial combination ( $1 / 2 \mathrm{MIC}$ of both gallic acid and ampicillin).

Effects of Combination Drugs on the Morphology of Bacterial Cells

The ultrastructural morphologies of $S$. Typhimurium (ATCC 14028) treated with the drug combination of gallic acid and ceftiofur and Escherichia coli (ATCC 25922) treated with 2 drug combinations (hamamelitannin-erythromycin and gallic acid-ampicillin) were studied to assess whether the combination drugs had any impact on the cellular architecture. The representative SEM images of gallic acid and ceftiofur-treated $S$. Typhimurium cells are shown in Figure 2. The SEM images revealed that untreated and gallic acid (1MIC)-treated $S$. Typhimurium cells had rod-like shape and were separated with perfect symmetry. In addition, binary fission of the bacteria was evident in the SEM images (Figure 2a and c). The cells treated with ceftiofur alone or in combination with gallic acid were found in a long rope-like shape, and 
no binary fission was evident, which is completely different from control cells. None of the cells were pitted, deformed or broken and the antibacterials had no effect on the cell wall or cytoplasmic membrane of the bacteria. The $E$. coli cells treated with hamamelitannin-erythromycin and gallic acid-ampicillin combinations also showed similar changes in cell length and binary fission without any effects on the cell wall or cytoplasmic membrane (data not shown).

Effects of Combination Drugs on Biofilm Inhibition and Viability

S. Typhimurium (ATCC 14028) biofilm formation in the presence of the gallic acid-ceftiofur drug combination and $E$. coli (ATCC 25922) biofilm formation in the presence of the hamamelitannin-erythromycin and gallic acid-ampicillin drug combinations were evaluated using a static biofilm assay. The effects of the combination antibacterials on the growth of planktonic and biofilm cells of $S$. Typhimurium and $E$. coli are shown in Figure 3. The inhibition of both planktonic and biofilm cells of these bacteria was more induced by the combination drugs than by the individual drugs in most cases. The $1 / 4 \mathrm{MIC}$ of the commercial antibiotics could significantly inhibit $S$. Typhimurium and E. coli biofilm formation when a lower amount of the respective phenolic compounds were applied together with these antibiotics.

The viability of the biofilms in the presence of the combination antibacterials was determined by staining the biofilms with BacLight live/dead stain and imaging with a CLSM. The reduction in biofilm viability with the combination antibacterial treatments is demonstrated by the results obtained with the CLSM. Figure 4 shows the CLSM images of $S$. Typhimurium and E. coli biofilms formed on a glass surface and treated with or without the combination antibacterials. The confocal micrograph of $48 \mathrm{~h} S$. Typhimurium and E. coli biofilms treated with combination antibacterials for $24 \mathrm{~h}$ displays a lower proportion of live cells (cells that are stained green) than those observed in the untreated controls. It is clearly visible that almost all the cells were alive in the control biofilm, while most of the cells were dead (cells that are stained red) after treatment with the combination antibacterials.

Effects of Combination Drugs on the Motility of Bacterial Cells

The effects of the antibacterial combinations on the swimming and swarming motilities of $S$. Typhimurium (ATCC 14028) and E. coli (ATCC 25922) were evaluated. Representative photographs of drug-treated swim and swarm plates are displayed in Figure 5. Table 2 shows the diameters of the swim and swarm zones. The results demonstrated that the hamamelitannin-erythromycin combination and the gallic acid-ampicillin combination significantly inhibited both the swimming and the swarming motilities of E. coli. Similarly, the swimming and swarming motilities of $S$. Typhimurium were noticeably inhibited by the gallic acid-ceftiofur combination. Moreover, the combination antibacterials showed better inhibitions of swimming and swarming motilities at sub-MIC concentrations compared to their individual effects at MIC concentrations.

Safety Profiles of Potent Phenolic Compounds

The effects of gallic acid and hamamelitannin on the viability of Rattus norvegicus small intestine cells (IEC-6) were investigated. The $\mathrm{IC}_{50}$ of gallic acid and hamamelitannin were $564.55 \mu \mathrm{M}$ and $988.54 \mu \mathrm{M}$, respectively. However, the inhibitory responses of these drugs were not completely concentration-dependent within the tested concentrations.

\section{Discussion}

There are recent reports indicating the resistance of several bacterial strains to different antibiotics that have been used in the treatment of infectious diseases of human and animals [46]. Thus, to combat infectious diseases associated with resistant pathogens, the development of alternative antimicrobial drugs is urgently needed $[47,48]$. The in vitro activities of all the tested phenolic compounds against resistant strains of Salmonella Typhimurium(Table 1) reflects that those compounds could be good candidates to minimize the development of bacterial resistance and to ensure clinical

Page 8/23 
treatment of bacterial infections. In the present study, the MIC results demonstrated the antibacterial activities of the phenolic compounds against all the tested strains of $S$. Typhimurium, E. coli and $S$. aureus, which have been shown to be resistant to one to eight out of ten antibiotics (Table 1). The potentials of these phenolic compounds were further explored through their combined interactions with commercial antibiotics, where they possessed synergistic effects with thiamphenicol and erythromycin against $S$. Typhimurium and $E$. coli and additive and/or indifferent effects with the other tested antibiotics. The time- and concentration-dependent inhibition assays also exposed that the combinations of phenolic compounds and commercial antibiotics more effectively inhibited the growth of $S$. Typhimurium and $E$. coli than the antibiotics alone. Furthermore, the combinations of phenolic compounds and commercial antibiotics demonstrated improved inhibition of biofilm formation and motility in $S$. Typhimurium and $E$. coli.

The MICs of the 5 phenolic compounds (epicatechin, epicatechin gallate, epigallocatechin, gallic acid and hamamelitannin) were investigated against QC strains of $S$. Typhimurium, $E$. coli and $S$. aureus and 5 clinical strains of $S$. Typhimurium. It has been reported that gallic acid can restrain the growth of many bacteria, including methicillinsensitive S. aureus, MRSA, E. coli, P. aeruginosa, and Salmonella typhi [49]. The results in Table 1 indicate that gallic acid possessed the strongest antibacterial activity among these phenolic compounds, followed by epigallocatechin, hamamelitannin, epicatechin gallate and epicatechin. Moreover, very convincing MIC values were obtained for gallic acid and epigallocatechin against the Gram-positive bacterium $S$. aureus. The MIC value of gallic acid against the QC strain of $S$. aureus $(128 \mu \mathrm{g} / \mathrm{mL})$ in this study is lower than those reported previously for five strains $(630 \mu \mathrm{g} / \mathrm{mL})$ [49], one single strain $(3200 \mu \mathrm{g} / \mathrm{mL})$ [50], or 18 strains isolated from clinical cases of human impetigo and furuncle lesions (8000 $\mu \mathrm{g} / \mathrm{mL})$ [51], while the MIC value was higher than that reported in another study using only two strains $(62.5 \mu \mathrm{g} / \mathrm{mL})$ [52]. The MIC values of gallic acid against $S$. Typhimurium $(256 \mu \mathrm{g} / \mathrm{mL})$ and $E$. coli $(1024 \mu \mathrm{g} / \mathrm{mL})$ in this study are lower than those reported previously $(2500 \mu \mathrm{g} / \mathrm{mL})$ [49]. The mean MICs of plant-derived epigallocatechin against $S$. aureus, $S$. Typhimurium and E. coli were reported to be $162 \pm 44,572 \pm 186$ and $733 \pm 121 \mu \mathrm{g} / \mathrm{mL}$, respectively [53]. The MIC value of pure epigallocatechin against $S$. aureus $(32 \mu \mathrm{g} / \mathrm{mL})$ in our study was lower than the previously reported MIC value $(162 \pm 44 \mu \mathrm{g} / \mathrm{mL})$ [53]. This lower MIC value for plant-derived epigallocatechin against $S$. aureus in the previous study compared to the MIC value for pure epigallocatechin in our study is might be because of the purity of the compound used. However, the MIC values for plant-derived epigallocatechin against $S$. Typhimurium and $E$. coli were comparable with the results of our study. Likewise, the MICs of epicatechin against S. aureus, S. Typhimurium and E. coli were 2500 $\mu \mathrm{g} / \mathrm{mL}$, which demonstrates the similarity between our results and previously published results [49].

It is always recommended to treat bacterial infections with a combination of antimicrobial agents to prevent the development of drug resistance and to improve efficacy. Drug combinations with synergistic interactions are generally considered to be more effective and, therefore, preferable [54]. Incidentally, synergistic effects were obtained from the combinations of thiamphenicol and gallic acid (FICl: 0.281), erythromycin and hamamelitannin (FICl: 0.375), and thiamphenicol and hamamelitannin (FICl: 0.50) against E. coli. The combination of erythromycin and epicatechin gallate against $S$. Typhimurium also showed synergistic antibacterial effects (FICl: 0.50). Moreover, additive effects were obtained from many combinations against $S$. Typhimurium (FICl: 0.502 0.750; n=16), S. aureus (FICl: 0.504 0.625; $\mathrm{n}=13)$ and $E$. coli (FICl: $0.502 \sim 0.625 ; \mathrm{n}=17)$. The rest of the combinations had indifferent effects against these three bacteria. Excellent in vitro activity combined with the synergistic effects with other antibacterial drugs underscores the potential utility of these phenolic compounds for the treatment of E. coli, S. Typhimurium and/or S. aureus-associated infections. The combinations of gallic acid and ceftiofur, hamamelitannin and erythromycin, and gallic acid and ampicillin, which have synergistic or additive antibacterial effects, against $S$. Typhimurium and $E$. coli were selected for further studies depending on both the clinical and commercial importance of each combination.

Time-kill assays are useful for the evaluation of the pharmacodynamic characteristics of new antimicrobial agents and to determine whether the effects of antibacterials are bacteriostatic or bactericidal [55]. According to our results, gallic acid and hamamelitannin alone or in combination with ceftiofur, ampicillin and erythromycin show bacteriostatic activity 
against the tested bacteria, as a reduction $\geq 99.9 \%$ of the inoculum was not observed compared to the growth control. At $1 / 2 \mathrm{MIC}$, both gallic acid and ceftiofur in combination were able to inhibit $S$. typhimurium in the first $8 \mathrm{~h}$ of incubation, similarly the $1 \mathrm{MIC}$ concentration of both drugs in combination demonstrated complete inhibition within the first $8 \mathrm{~h}$. After the first $8 \mathrm{~h}$ and $12 \mathrm{~h}$, the bacteria treated with $1 / 2 \mathrm{MIC}$ and $1 \mathrm{MIC}$ concentrations of the combination antibacterials started their log phase, respectively. At the end of the incubation period ( $24 \mathrm{~h})$, a greater than 3 -fold reduction in the inoculum concentration with $1 / 2 \mathrm{MIC}$ of gallic acid and ceftiofur and an approximately 7 -fold lower inoculums concentration with $1 \mathrm{MIC}$ of gallic acid and ceftiofur were achieved in contrast to the control. The $1 \mathrm{MIC}$ of both hamamelitannin and erythromycin together inhibited the growth of $E$. coli completely within the first $12 \mathrm{~h}$, after which the bacteria started to revive. After the incubation period, the inoculum concentrations were reduced by several-fold compared to the control for the bacteria treated with gallic acid and hamamelitannin alone or in combination with ceftiofur, erythromycin or ampicillin, indicating that these phenolic compounds alone and in combination with ceftiofur, erythromycin and ampicillin have bacteriostatic effects.

To investigate the antibacterial mode of action, it is essential to evaluate changes in the bacterial cell membrane permeability, integrity, morphology and surface characteristics $[56,57]$. The physiological and morphological changes in E. coli and $S$. Typhimurium were observed by SEM after treatment with gallic acid and hamamelitannin alone and in combination with ceftiofur, erythromycin and ampicillin. The results showed a direct effect of the combination antibacterials on the tested pathogens. The treated bacterial cells showed obvious morphological changes compared to untreated cells. Almost all treated bacterial cells were found as long and rope-like, with no binary fission, which is completely different from the untreated control cells. These observations indicated that the combination antibacterials had a major effect on the bacterial cell division. The effects of phenolic compounds on the quorum sensing of $C$. violaceum were evaluated by agar disk diffusion assays, which demonstrated that these compounds have no noticeable anti-quorum sensing effect (data not shown).

S. Typhimurium (ATCC 14028) biofilm formation in the presence of the gallic acid-ceftiofur combination and $E$. coli (ATCC 25922) biofilm formation in the presence of the hamamelitannin-erythromycin and gallic acid-ampicillin combinations were evaluated using a static biofilm assay. The inhibition of both planktonic and biofilm cells of these bacteria was induced by the combination drugs more than the individual drugs in most cases. The surviving and dead biofilm populations in the presence of the combination antibacterials were determined by imaging the BacLight live/dead-stained biofilm by CLSM. These results revealed that in addition to being bacteriostatic, the gallic acidceftiofur, hamamelitannin-erythromycin and gallic acid-ampicillin combinations also appeared to act against the biofilm matrix. The large effect of the gallic acid-ceftiofur and gallic acid-ampicillin combinations against the biofilm cells of $S$. Typhimurium and E. coli, respectively, might be due to the small molecular size of gallic acid (170.12 g/mol), which easily penetrates into the biofilm. Subsequently, these combination antibacterials seem to destroy the biofilm matrix, resulting in the detachment of cells and thus the biofilm cells become more exposed and susceptible.

Motility is one of the pathogenic phenotypes of bacteria that contribute to the migration and dispersion of bacteria and their escape from the host immune response [38]. Flagella are known to be involved in swimming motility and play a role in biofilm formation, as well as swarming motility [53]. Recent reports mentioned that, similar to biofilms, swarming cells also show a higher degree of resistance to a variety of antibiotics [39, 59]. In this study, we investigated the ability of the gallic acid-ceftiofur, hamamelitannin-erythromycin and gallic acid-ampicillin combinations to inhibit the swarming and swimming activities of $S$. Typhimurium and E. coli. The results (Figure 3) showed significant inhibition of swimming and swarming motilities with the addition of gallic acid-ceftiofur, hamamelitannin-erythromycin and gallic acid-ampicillin combinations. The lack of swimming and swarming motilities in the presence of the combination antibacterials suggest that these agents might have some effects on flagella-related processes, namely, flagella biosynthesis, rotation, and chemotaxis, which may lead to decreased swimming and swarming activities.

Page $10 / 23$ 
The evaluation of the safety/toxicity profiles of any drug is desirable and an essential part of the investigation of the pharmacological effects. Especially considering that the combinations of gallic acid-ceftiofur, hamamelitanninerythromycin and gallic acid-ampicillin were found to be active against intestinal bacteria. Moreover, humans are very often exposed to ingested contaminants or toxins. Although virtually all organs and tissues are exposed, once the ingested toxins cross the intestinal wall, the gut is the first organ exposed and experiences the highest concentrations/doses of toxins. Many of these toxins are able to affect intestinal functions in both animals and humans [60]. For these reasons, toxicological studies focusing on the intestine are of primary importance. Hence, the cytotoxic effects of gallic acid and hamamelitannin were investigated in a small intestine cell line of Rattus norvegicus (IEC-6) to determine whether these compounds have any adverse effects on intestine. The $\mathrm{IC}_{50}$ values of gallic acid and hamamelitannin in Rattus norvegicus (IEC-6) cells were $564.55 \mu \mathrm{M}$ and $988.54 \mu \mathrm{M}$, respectively. The effects of gallic acid and hamamelitannin on cell viability were evaluated previously with different cell lines and found to have cytoprotective effects or no adverse effects in cell viability [61, 62].

\section{Conclusion}

Together with all the promising in vitro assay findings, it can be concluded that gallic acid and epigallocatechin are potent and noble candidates to eradicate Gram-positive bacteria, such as $S$. aureus. Gallic acid and hamamelitannin alone and in combination with commercial antibiotics can be promising agents against Gram-negative bacteria as well, including $S$. Typhimurium and $E$. coli. The effects of gallic acid and hamamelitannin are bacteriostatic, and the use of these 2 phenolic compounds in combination with commercial antibiotics can more effectively interfere with the biofilm than the antibiotics alone, which is crucial to develop new antimicrobials and/or improve the efficacy of existing antimicrobials to reduce the pathogenicity associated with these bacteria. All the findings of this study suggest that gallic acid and hamamelitannin are safe and can serve as potential medications to treat $S$. Typhimurium, $E$. coli and $S$. aureus infections in the future. Further study is recommended to determine the specific mechanisms of the synergistic antibacterial effects of these compounds and to confirm their efficacy in in vivo systems.

\section{Abbreviations}

AMP: ampicillin; CDC: canter for disease control and prevention; CEF: ceftiofur; CLSI: clinical and laboratory standard institute; CLSM: confocal laser scanning microscope; DDW: double-distilled water; DMEM: dulbecco's modified eagle's medium; ERY: erythromycin; FIC: Fractional inhibitory concentration; FICI: FIC index; GA: gallic acid; $\mathrm{GIC}_{50}: 50 \%$ growth inhibition concentrations; HAMA: hamamelitannin; $\mathrm{IC}_{50}$ : 50\% inhibitory concentrations; MDR: multidrug-resistant; MHA: mueller hinton agar; MHB: mueller hinton broth; MIC: minimum inhibitory concentrations; NB: nutrient broth; NTME: Nymphaea tetragona 50\% methanol extract; OD: optical density; PBS: phosphate buffer saline; QC: quality control; QS: quorum sensing; SEM: scanning electronic microscope; TSB: trypticase soy broth; WHO: world health organization.

\section{Declarations}

\section{Competing Interests}

None of the authors have any conflicts of interest to declare.

\section{Availability of Data and Materials}

Data will be shared upon request to the corresponding author.

\section{Ethics Approval and Consent to Participate}


All procedures have been approved by the Bioethical Committee of Animal and Plant Quarantine Agency, Republic of Korea.

\section{Authors' Contributions}

MAH conceived the study, and involved in conception, design, acquisition of data, analysis, interpretation, drafting and critically revising the manuscript; JWK and HCP were involved in some of the experiments and reviewed the manuscript; JWK, SUP and KJL analyzed the data and approved the final version of the manuscript. All authors read and approved the final manuscript.

\section{Authors' Information}

${ }^{1}$ Veterinary Drugs \& Biologics Division, Animal and Plant Quarantine Agency, Gimcheon-si 39660, Republic of Korea.

${ }^{2}$ Laboratory of Veterinary Pharmacokinetics and Pharmacodynamics, College of Veterinary Medicine, Kyungpook National University, Bukgu, Daegu 41566, Republic of Korea.

\section{Acknowledgements}

The authors would like to thank all members of the laboratory of antibiotics and therapeutics, Veterinary Drugs \& Biologics Division, Animal and Plant Quarantine Agency for their support during these studies.

\section{Funding}

This study was supported by Veterinary Science Research Project grants from the Korean Animal and Plant Quarantine Agency (Grant no. B-1543073-2017-17-0101).

\section{References}

1. Fact sheet: the top 10 causes of death. World Health Organization, Geneva. 2019. http://www.who.int/mediacentre/factsheets/fs310/en/index2.html. Accessed 26 Mar 2019.

2. Farooqui A, Khan A, Borghetto I, Kazmi SU, Rubino S, Paglietti B. Synergistic antimicrobial activity of Camellia sinensis and Juglans regia against multidrug-resistant bacteria. PLoS One. 2015;10(2):e0118431. doi: 10.1371/journal.pone.0118431

3. Golkar Z, Bagasra O, Pace DG. Bacteriophage therapy: a potential solution for the antibiotic resistance crisis. J Infect Dev Ctries. 2014;8(2):129-36. doi: 10.3855/jidc.3573

4. Gould IM, Bal AM. New antibiotic agents in the pipeline and how they can help overcome microbial resistance. Virulence. 2013;4(2):185-91. doi: 10.4161/viru.22507

5. Wright GD. Something old, something new: revisiting natural products in antibiotic drug discovery. Can J Microbiol. 2014;60(3):147-54. doi: 10.1139/cjm-2014-0063

6. Sengupta S, Chattopadhyay MK, Grossart HP. The multifaceted roles of antibiotics and antibiotic resistance in nature. Front Microbiol. 2013;4:47. doi: 10.3389/fmicb.2013.00047

7. Antibiotic Resistance Threats in the United States. Centers for Disease Control and Prevention, U.S. Department of Health and Human Services. 2013. https://www.cdc.gov/drugresistance/pdf/ar-threats-2013-508.pdf. Accessed 26 Mar 2019 
8. Shrestha L. Life expectancy in the United States. Congressional research service report. 2005.

https://www.research.policyarchive.org/2355.pdf. Accessed 26 Mar 2019

9. Viswanathan VK. Off-label abuse of antibiotics by bacteria. Gut Microbes. 2014;5(1):3-4. doi: 10.4161/gmic.28027

10. Read AF, Woods RJ. Antibiotic resistance management. Evol Med Public Health. 2014;2014(1):147. doi:

10.1093/emph/eou024

11. Nature. The antibiotic alarm. Nature. 2013;495(7440):141. doi: 10.1038/495141a

12. Lushniak BD. Antibiotic resistance: a public health crisis. Public Health Rep. 2014;129(4):314-6. doi:

$10.1177 / 003335491412900402$

13. Gross M. Antibiotics in crisis. Curr Biol. 2013;23(24):R1063-5. doi: 10.1016/j.cub.2013.11.057

14. Piddock LJ. The crisis of no new antibiotics-what is the way forward? Lancet Infect Dis. 2012;12(3):249-53. doi: 10.1016/S1473-3099(11)70316-4

15. Bartlett JG, Gilbert DN, Spellberg B. Seven ways to preserve the miracle of antibiotics. Clin Infect Dis. 2013;56(10):1445-50. doi: 10.1093/cid/cit070

16. Michael CA, Dominey-Howes D, Labbate M. The antimicrobial resistance crisis: causes, consequences, and management. Front Public Health. 2014;2:145. doi: 10.3389/fpubh.2014.00145

17. Rossolini GM, Arena F, Pecile P, Pollini S. Update on the antibiotic resistance crisis. Curr Opin Pharmacol. 2014;18:56-60. doi: 10.1016/j.coph.2014.09.006

18. Tacconelli E, Magrini N. Global priority list of antibiotic-resistant bacteria to guide research, discovery, and development of new antibiotics. World Health Organization, Geneva. 2017.

https://www.who.int/medicines/publications/WHO-PPL-Short_Summary_25Feb-ET_NM_WHO.pdf?ua=1. Accessed 26 Mar 2019

19. Courtney CM, Goodman SM, Nagy TA, Levy M, Bhusal P, Madinger NE, Detweiler CS, Nagpal P, Chatterjee A. Potentiating antibiotics in drug-resistant clinical isolates via stimuli-activated superoxide generation. Sci Adv. 2017;3(10):e1701776. doi: 10.1126/sciadv.1701776

20. Patra JK, Baek KH. Antibacterial activity and synergistic antibacterial potential of biosynthesized silver nanoparticles against foodborne pathogenic bacteria along with its anticandidal and antioxidant effects. Front Microbiol. 2017;8:167. doi: 10.3389/fmicb.2017.00167

21. Acharyya S, Sarkar P, Saha DR, Patra A, Ramamurthy T, Bag PK. Intracellular and membrane-damaging activities of methyl gallate isolated from Terminalia chebula against multidrug-resistant Shigella spp. J Med Microbiol. 2015;64(8):901-9. doi: 10.1099/jmm.0.000107

22. Ozcan T, Akpinar-Bayizit A, Yilmaz-Ersan L, Delikanli B. Phenolics in human health. Int J Chem Eng Appl. 2014;5(5):393-6. doi: 10.7763/IJCEA.2014.V5.416

23. Hossain MA, Lee SJ, Park JY, Reza MA, Kim TH, Lee KJ, Suh JW, Park SC. Modulation of quorum sensing-controlled virulence factors by Nymphaea tetragona (water lily) extract. J Ethnopharmacol. 2015;174:482-91. doi:

10.1016/j.jep.2015.08.049

Page $13 / 23$ 
24. Hossain MA, Park JY, Kim JY, Suh JW, Park SC. Synergistic effect and antiquorum sensing activity of Nymphaea tetragona (water lily) extract. Biomed Res Int. 2014;2014:562173. doi: 10.1155/2014/562173

25. Pimenta ADL, Chiaradia-Delatorre LD, Mascarello A, de Oliveira KA, Leal PC, Yunes RA, de Aguiar CB, Tasca Cl, Nunes RJ, Smania A Jr. Synthetic organic compounds with potential for bacterial biofilm inhibition, a path for the identification of compounds interfering with quorum sensing. Int J Antimicrob Agents 2013;42(6):519-23. doi:

10.1016/j.ijantimicag.2013.07.006

26. Hossain MA, Lee SJ, Park NH, Mechesso AF, Birhanu BT, Kang J, Reza MA, Suh JW, Park SC. Impact of phenolic compounds in the acyl homoserine lactone-mediated quorum sensing regulatory pathways. Sci Rep. 2017;7:10618. doi: 10.1038/s41598-017-10997-5

27. Birhanu BT, Park NH, Lee SJ, Hossain MA, Park SC. Inhibition of Salmonella Typhimurium adhesion, invasion, and intracellular survival via treatment with methyl gallate alone and in combination with marbofloxacin. Vet Res. 2018;49(1):101. doi: 10.1186/s13567-018-0597-8

28. Yong YC, Zhong JJ. Impacts of quorum sensing on microbial metabolism and human health. Adv Biochem Eng Biotechnol. 2013;131:25-61. doi: 10.1007/10_2012_138

29. Wang Y. The anti-oxidation and anti-microbial activities of tea polyphenols and its increased reagents. J Biol. 2007;24:54-6.

30. Methods for Dilution Antimicrobial Susceptibility Tests for Bacteria that Grow Aerobically. CLSI Approved Standards M7-A5. Clinical and Laboratory Standards Institute, Wayne. 2000. https://clsi.org/media/1928/m07ed11_sample.pdf. Accessed 26 Mar 2019.

31. Reddy VM, Einck L, Nacy CA. In vitro antimycobacterial activities of capuramycin analogues. Antimicrob Agents Chemother. 2008;52(2):719-21. doi: 10.1128/AAC.01469-07

32. Shalit I, Shadkchan Y, Samra Z, Osherov N. In vitro synergy of caspofungin and itraconazole against Aspergillus spp.: MIC versus minimal effective concentration end points. Antimicrob Agents Chemother. 2003;47(4):1416-8. doi: 10.1128/AAC.47.4.1416-1418.2003

33. Murtey M, Ramasamy P. Sample preparations for scanning electron microscopy-life sciences. In: Janecek M, Kral R, editors. Modern Electron Microscopy in Physical and Life Sciences. IntechOpen. London, United Kingdom, 2016. P. 16185.

34. Alvarez MV, Moreira MR, Ponce A. Antiquorum sensing and antimicrobial activity of natural agents with potential use in food. J Food Saf. 2012;32(3):379-87. doi: 10.1111/j.1745-4565.2012.00390.x

35. McGrath DM, Barbu EM, Driessen WH, Lasco TM, Tarrand JJ, Okhuysen PC, Kontoyiannis DP, Sidman RL, Pasqualini R, Arap W. Mechanism of action and initial evaluation of a membrane active all-D-enantiomer antimicrobial peptidomimetic. Proc Natl Acad Sci USA. 2013;110(9):3477-82. doi: 10.1073/pnas.1221924110

36. Zhao T, Liu Y. N-acetylcysteine inhibit biofilms produced by Pseudomonas aeruginosa. BMC Microbiol 2010;10:140. doi: 10.1186/1471-2180-10-140

37. Periasamy S, Joo HS, Duong AC, Bach TH, Tan VY, Chatterjee SS, Cheung GY, Otto M. How Staphylococcus aureus biofilms develop their characteristic structure. Proc Natl Acad Sci USA. 2012;109(4):1281-6. doi:

10.1073/pnas. 1115006109

Page $14 / 23$ 
38. Zhuang Y, Chen W, Yao F, Huang Y, Zhou S, Li H, Zhang Z, Cai C, Gao Y, Peng Q. Short-term pretreatment of subinhibitory concentrations of gentamycin inhibits the swarming motility of Escherichia coli by down-regulating the succinate dehydrogenase gene. Cell Physiol Biochem. 2016;39(4):1307-16. doi: 10.1159/000447835

39. Kim W, Killam T, Sood V, Surette MG. Swarm-cell differentiation in Salmonella enterica serovar Typhimurium results in elevated resistance to multiple antibiotics. J Bacteriol. 2003;185(10):3111-7. doi: 10.1128/JB.185.10.3111-3117.2003

40. 40. Lai LH, Fu QH, Liu Y, Jiang K, Guo QM, Chen QY, Yan B, Wang QQ, Shen JG. Piperine suppresses tumor growth and metastasis in vitro and in vivo in a 4T1 murine breast cancer model. Acta Pharmacol Sin. 2012;33(4):523-30. doi: 10.1038/aps.2011.209

41. Performance Standards for Antimicrobial Disk and Dilution Susceptibility Testing for Bacteria Isolated From Animals. CLSI Approved Standards M31-A3. Clinical and Laboratory Standards Institute, Wayne. 2008. https://www.dbt.univr.it/documenti/Occorrenzalns/matdid/matdid485539.pdf. Accessed 26 Mar 2019.

42. Breakpoint tables for interpretation of MICs and zone diameters. Version 9.0. European Committee on Antimicrobial Susceptibility Testing, Basel. 2019. http://www.eucast.org/clinical_breakpoints/. Accessed 26 Mar 2019.

43. Sanhueza L, Melo R, Montero R, Maisey K, Mendoza L, Wilkens M. Synergistic interactions between phenolic compounds identified in grape pomace extract with antibiotics of different classes against Staphylococcus aureus and Escherichia coli. PLoS ONE. 2017;12(2):e0172273. doi: 10.1371/journal.pone.0172273

44. Clinical Microbiology and Infection. Statement 1996 CA-SFM Zone sizes and MIC breakpoints for non-fastidious organisms. Clin Microbiol Infect. 1996;2 Suppl 1: S46-9. doi: 10.1111/j.1469-0691.1996.tb00875.x

45. Wei CF, Chang SK, Shien JH, Kuo HC, Chen WY, Chou CC. Synergism between two amphenicol of antibiotics, florfenicol and thiamphenicol, against Staphylococcus aureus. Vet Rec. 2016;178(13):319. doi: 10.1136/vr.103554

46. Davies J, Davies D. Origins and evolution of antibiotic resistance. Microbiol Mol Biol Rev. 2010;74(3):417-33. doi: 10.1128/MMBR.00016-10

47. Berahou A, Auhmani A, Fdil N, Benharref A, Jana M, Gadhi CA. Antibacterial activity of Quercus ilex bark's extracts. J Ethnopharmacol. 2007;112(3):426-9. doi: 10.1016/j.jep.2007.03.032

48. Salomao K, Pereira PR, Campos LC, Borba CM, Cabello PH, Marcucci MC, De Castro SL. Brazilian propolis: correlation between chemical composition and antimicrobial activity. Evid Based Complement Alternat Med. 2008;5(3):317-24. doi: 10.1093/ecam/nem058

49. Fu L, Lu W, Zhou X. Phenolic compounds and in vitro antibacterial and antioxidant activities of three tropic fruits: persimmon, guava, and sweetsop. BioMed Res Int. 2016;2016:4287461. doi: 10.1155/2016/4287461

50. Kubo I, Fujita K, Nihei K. Molecular design of multifunctional antibacterial agents against methicillin resistant Staphylococcus aureus (MRSA). Bioorg Med Chem. 2003;11(19):4255-62. doi: 10.1016/S0968-0896(03)00433-4

51. Akiyama H, Fujii K, Yamasaki O, Oono T, Iwatsuki K. Antibacterial action of several tannins against Staphylococcus aureus. J Antimicrob Chemother. 2001;48(4):487-91. doi: 10.1093/jac/48.4.487

52. Shibata H, Kondo K, Katsuyama R, Kawazoe K, Sato Y, Murakami K, Takaishi Y, Arakaki N, Higuti T. Alkyl gallates, intensifiers of beta-lactam susceptibility in methicillin-resistant Staphylococcus aureus. Antimicrob Agents Chemother. 2005;49(2):549-55. doi: 10.1128/AAC.49.2.549-555.2005

Page $15 / 23$ 
53. Taguri T, Tanaka T, Kouno I. Antimicrobial activity of 10 different plant polyphenols against bacteria causing foodborne disease. Biol Pharm Bull. 2004;27:1965-9. doi: 10.1248/bpb.27.1965

54. Dubuisson T, Bogatcheva E, Krishnan MY, Collins MT, Einck L, Nacy CA, Reddy VM. In vitro antimicrobial activities of capuramycin analogues against non-tuberculous mycobacteria. J Antimicrob Chemother. 2010;65(12):2590-7. doi: $10.1093 / \mathrm{jac} / \mathrm{dkq} 372$

55. Pfaller MA, Sheehan DJ, Rex JH. Determination of fungicidal activities against yeasts and molds: lessons learned from bactericidal testing and the need for standardization. Clin Microbiol Rev. 2004;17(2):268-80. doi: 10.1128/CMR.17.2.268-280.2004

56. Diao W-R, Hu Q-P, Zhang H, Xu J-G. Chemical composition, antibacterial activity and mechanism of action of essential oil from seeds of fennel (Foeniculum vulgare Mill.). Food Control. 2014;35(1):109-16. doi: 10.1016/j.foodcont.2013.06.056

57. Sadiq MB, Tarning J, Aye Cho TZ, Anal AK. Antibacterial activities and possible modes of action of Acacia nilotica (L.) Del. against multidrug-resistant Escherichia coli and Salmonella. Molecules. 2017;22(1):47. doi: 10.3390/molecules22010047

58. de la Fuente-Nunez C, Korolik V, Bains M, Nguyen U, Breidenstein EB, Horsman S, Lewenza S, Burrows L, Hancock RE. Inhibition of bacterial biofilm formation and swarming motility by a small synthetic cationic peptide. Antimicrob Agents Chemother. 2012;56(5):2696-704. doi: 10.1128/AAC.00064-12

59. Lai S, Tremblay J, Deziel E. Swarming motility: a multicellular behaviour conferring antimicrobial resistance. Environ Microbiol. 2009;11(1):126-36. doi: 10.1111/j.1462-2920.2008.01747.x

60. Grenier B, Applegate TJ. Modulation of intestinal functions following mycotoxin ingestion: meta-analysis of published experiments in animals. Toxins. 2013;5(2):396-430. doi: 10.3390/toxins5020396

61. Yang DJ, Moh SH, Son DH, You S, Kinyua AW, Ko CM, Song M, Yeo J, Choi YH, Kim KW. Gallic acid promotes wound healing in normal and hyperglucidic conditions. Molecules. 2016;21(7):E899. doi: 10.3390/molecules21070899

62. Masaki H, Atsumi T, Sakurai H. Protective activity of hamamelitannin on cell damage of murine skin fibroblasts induced by UVB irradiation. J Dermatol Sci. 1995;10(1):25-34. doi: 10.1016/0923-1811(95)93711-9

\section{Tables}

Table 1: Minimum Inhibition Concentration of commercial antibiotics and phenolic compounds against different strains. 


\begin{tabular}{|c|c|c|c|c|c|c|c|c|}
\hline \multirow[t]{6}{*}{ Antimicrobials } & \multicolumn{8}{|c|}{ Minimum Inhibition Concentration (MIC, $\mu \mathrm{g} / \mathrm{mL}$ ) } \\
\hline & \multicolumn{6}{|c|}{ Salmonella enterica serovar Typhimurium } & \multirow{5}{*}{$\begin{array}{l}\text { Escherichia } \\
\text { coli } \\
\text { ATCC } \\
25922\end{array}$} & \multirow{5}{*}{$\begin{array}{l}\text { Staphylococcus } \\
\text { aureus } \\
\text { ATCC } 25923\end{array}$} \\
\hline & ATCC & V08-S- & V15-S- & SAL & SAL & SAL & & \\
\hline & \multirow[t]{3}{*}{14028} & HA- & HA- & 109 & 202 & 224 & & \\
\hline & & $06-$ & 02- & & & & & \\
\hline & & $(170)$ & $(210)$ & & & & & \\
\hline Amoxicillin & $<0.5$ & 256 & 1 & 256 & 256 & 256 & 1 & 0.25 \\
\hline Ampicillin & 1 & 512 & 512 & 512 & 512 & 512 & 2 & 0.125 \\
\hline Cefotaxime & $\leq 2$ & $\leq 2$ & $\leq 2$ & 512 & 128 & 128 & 0.125 & 2 \\
\hline Ceftiofur & $<1$ & $<1$ & 1 & 128 & 64 & 64 & 1 & 1 \\
\hline Erythromycin & 128 & 32 & 16 & 512 & 1024 & 512 & 128 & 0.5 \\
\hline Florfenicol & 8 & 8 & 4 & 64 & 32 & 64 & 8 & 4 \\
\hline Marbofloxacin & 0.062 & 0.25 & 0.25 & 2 & 2 & 4 & 0.25 & 0.25 \\
\hline Norfloxacin & 0.25 & 4 & 0.5 & 4 & 16 & 8 & 0.5 & 0.5 \\
\hline Penicillin G & 8 & 1024 & 32 & $>1024$ & $>1024$ & $>1024$ & 16 & 0.125 \\
\hline Thiamphenicol & 128 & 64 & 128 & 256 & 512 & 512 & 256 & 16 \\
\hline Epicatechin & $>1024$ & $>1024$ & $>1024$ & $>1024$ & $>1024$ & $>1024$ & $\geq 1024$ & $\geq 1024$ \\
\hline Epicatechin & $>512$ & 512 & $>512$ & $>512$ & $>512$ & $>512$ & 1024 & $\geq 1024$ \\
\hline gallate & & & & & & & & \\
\hline Epigallocatechin & 1024 & 512 & 512 & 512 & 512 & 512 & 512 & 32 \\
\hline Gallic acid & 256 & 256 & 256 & 256 & 256 & 256 & 1024 & 128 \\
\hline Hamamelitannin & 512 & 512 & 1024 & 1024 & 1024 & 1024 & 2048 & $\geq 2048$ \\
\hline
\end{tabular}


Table 2: Effect of ceftiofur-gallic acid combination on the swimming and swarming motilities of Salmonella enterica serovar Typhimurium (ATCC14028), and erythromycin-hamamelitannin and ampicillin-gallic acid combination on the swimming and swarming motilities of Escherichia coli (ATCC25922).

\begin{tabular}{|c|c|c|c|}
\hline Strains & Treatment Groups & $\begin{array}{l}\text { Swarming }(\mathrm{mm}) \\
(\text { mean } \pm \mathrm{SD})\end{array}$ & $\begin{array}{l}\text { Swimming (mm) } \\
(\text { mean } \pm S D)\end{array}$ \\
\hline \multirow{6}{*}{$\begin{array}{l}\text { Salmonella enterica serovar } \\
\text { Typhimurium }\end{array}$} & Control & $9.67 \pm 2.08^{\mathrm{a}}$ & $26.67 \pm 2.52^{\mathrm{a}}$ \\
\hline & Ceftiofur MIC & $2.00 \pm 1.00^{\mathrm{d}}$ & $5.33 \pm 2.31^{\mathrm{c}}$ \\
\hline & Gallic acid MIC & $6.33 \pm 1.15^{b}$ & $7.00 \pm 1.00^{\mathrm{b}}$ \\
\hline & Ceftiofur MIC + Gallic acid & $1.33 \pm 0.58^{\mathrm{e}}$ & $0.00 \pm 0.00$ \\
\hline & MIC & & \\
\hline & $\begin{array}{l}\text { Ceftiofur } \square \text { MIC + Gallic acid } \\
\square \mathrm{MIC}\end{array}$ & $3.33 \pm 1.15^{\mathrm{c}}$ & $2.33 \pm 1.53^{\mathrm{d}}$ \\
\hline \multirow[t]{7}{*}{ Escherichia coli } & Control & $23.33 \pm 2.08^{a}$ & $22.00 \pm 1.73^{a}$ \\
\hline & Erythromycin MIC & $6.67 \pm 1.15^{b}$ & $5.67 \pm 0.58^{\mathrm{c}}$ \\
\hline & Hamamelitannin MIC & $3.33 \pm 0.58^{c}$ & $7.33 \pm 1.53^{b}$ \\
\hline & Erythromycin MIC + & $0.00 \pm 0.00$ & $0.00 \pm 0.00$ \\
\hline & Hamamelitannin MIC & & \\
\hline & Erythromycin $\mathrm{GMIC}+$ & $0.00 \pm 0.00$ & $2.67 \pm 0.58^{d}$ \\
\hline & Hamamelitannin $\square \mathrm{MIC}$ & & \\
\hline \multirow[t]{6}{*}{ Escherichia coli } & Control & $21.67 \pm 2.52^{\mathrm{a}}$ & $21.33 \pm 3.06^{\mathrm{a}}$ \\
\hline & Ampicillin MIC & $11.33 \pm 1.53^{b}$ & $5.67 \pm 1.15^{\mathrm{b}}$ \\
\hline & Gallic acid MIC & $4.00 \pm 1.73^{\mathrm{c}}$ & $4.33 \pm 1.53^{\mathrm{c}}$ \\
\hline & Ampicillin MIC + Gallic acid & $0.00 \pm 0.00$ & $1.67 \pm 1.53^{\mathrm{d}}$ \\
\hline & MIC & & \\
\hline & $\begin{array}{l}\text { Ampicillin } \square \mathrm{MIC}+\text { Gallic acid } \\
\square \mathrm{MIC}\end{array}$ & $3.67 \pm 1.15^{\mathrm{c}}$ & $4.00 \pm 1.00^{\mathrm{c}}$ \\
\hline
\end{tabular}

MIC: minimum inhibitory concentration. Different superscript letters indicate statistical significance $(P<$ 0.05).

\section{Figures}



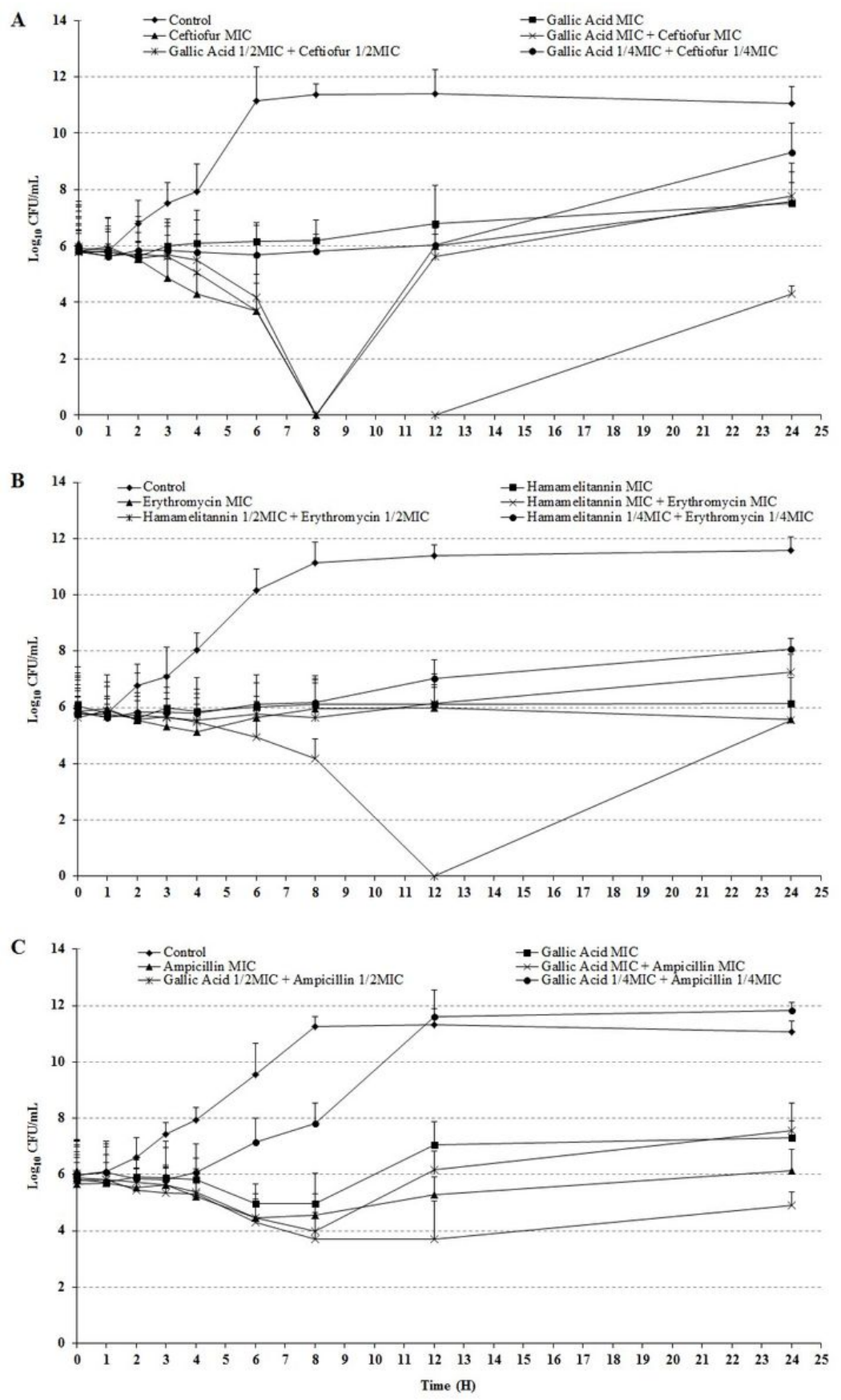

\section{Figure 1}

Time-kill curves of (A) Salmonella enterica serovar Typhimurium (ATCC14028), (B) Escherichia coli (ATCC25922), and (C) Escherichia coli (ATCC25922) in presence of gallic acid-ceftiofur, hamamelitannin-erythromycin and gallic acidampicillin combinations, respectively. MIC, minimum inhibitory concentration. 

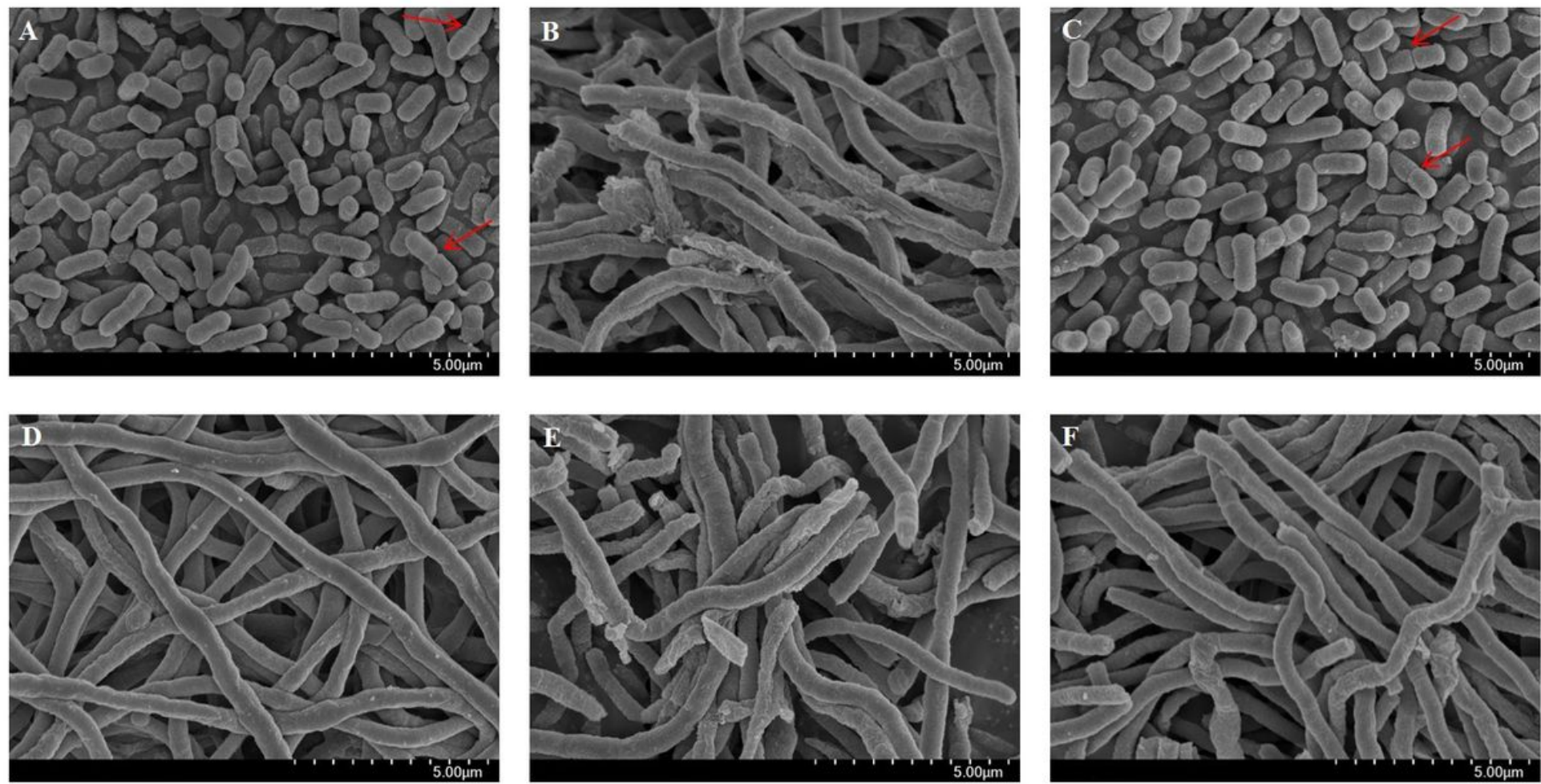

Figure 2

Effect of antibacterial combination on the ultrastructure morphology of bacterial cells. Representative images of Salmonella enterica serovar Typhimurium (ATCC14028) cells captured by scanning electronic microscope after treatment with gallic acid and ceftiofur. Salmonella enterica serovar Typhimurium cells treated with (A) no drug, (B) $1 \mathrm{MIC}$ of ceftiofur, (C) $1 \mathrm{MIC}$ of gallic acid, (D) $1 \mathrm{MIC}$ of ceftiofur and $1 \mathrm{MIC}$ of gallic acid, (E) $1 \frac{1}{2} \mathrm{MIC}$ of ceftiofur and $1 \frac{1}{2} \mathrm{MIC}$ of gallic acid, and (F) $1 / 4 \mathrm{MIC}$ of ceftiofur and $1 / 4 \mathrm{MIC}$ of gallic acid. GA, gallic acid; CEF, ceftiofur; MIC, minimum inhibitory concentration. Arrows indicate binary fission.
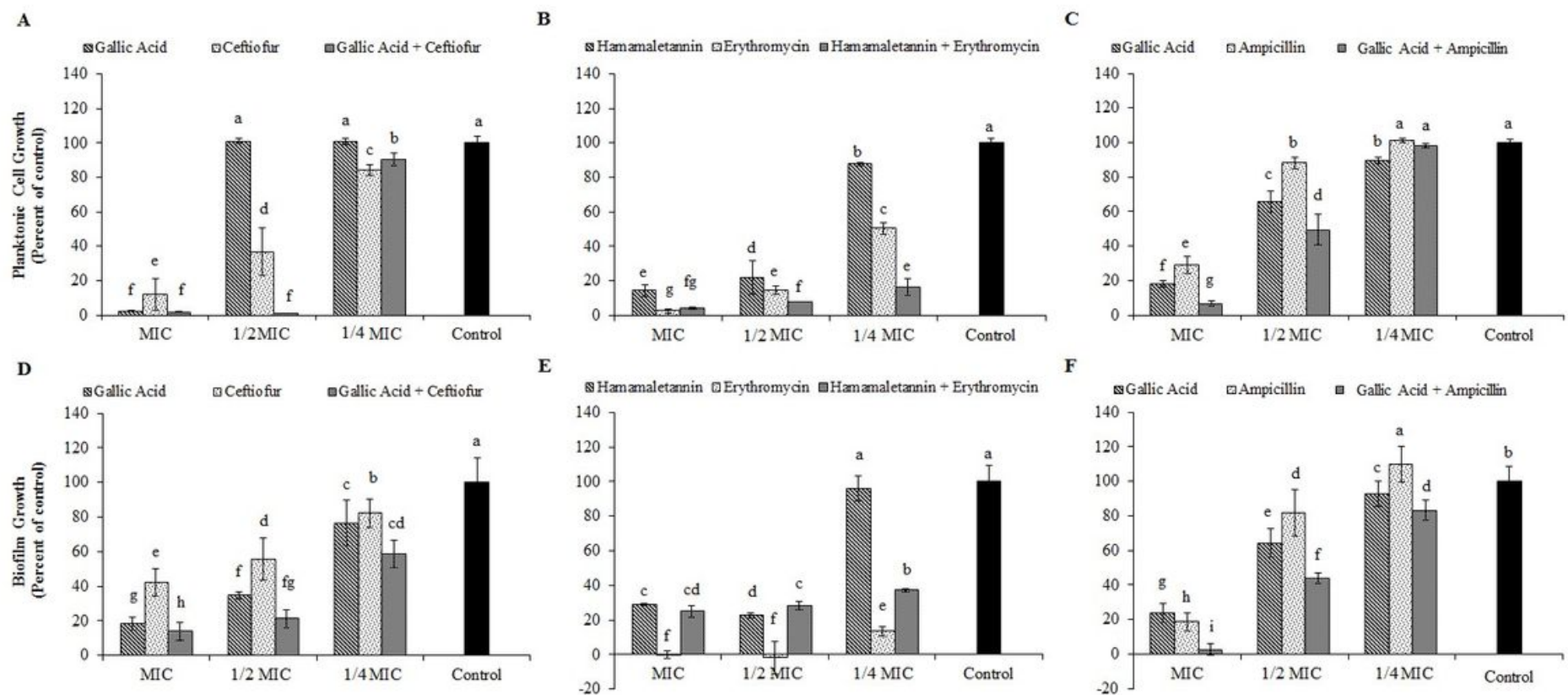

Figure 3 
Effect of antibacterial combination on the on the growth of planktonic cells (upper panel) and biofilm cells (lower panel). Effect of gallic acid-ceftiofur combination on (A) planktonic and (D) biofilm cells of Salmonella enterica serovar Typhimurium (ATCC14028). Effects of hamamelitannin-erythromycin combination on (B) planktonic and (E) biofilm cells, and gallic acid-ampicillin combination on (C) planktonic and (F) biofilm cells of Escherichia coli (ATCC25922). MIC: minimum inhibitory concentration. Different superscript letters indicate statistical significance $(P<0.05)$.

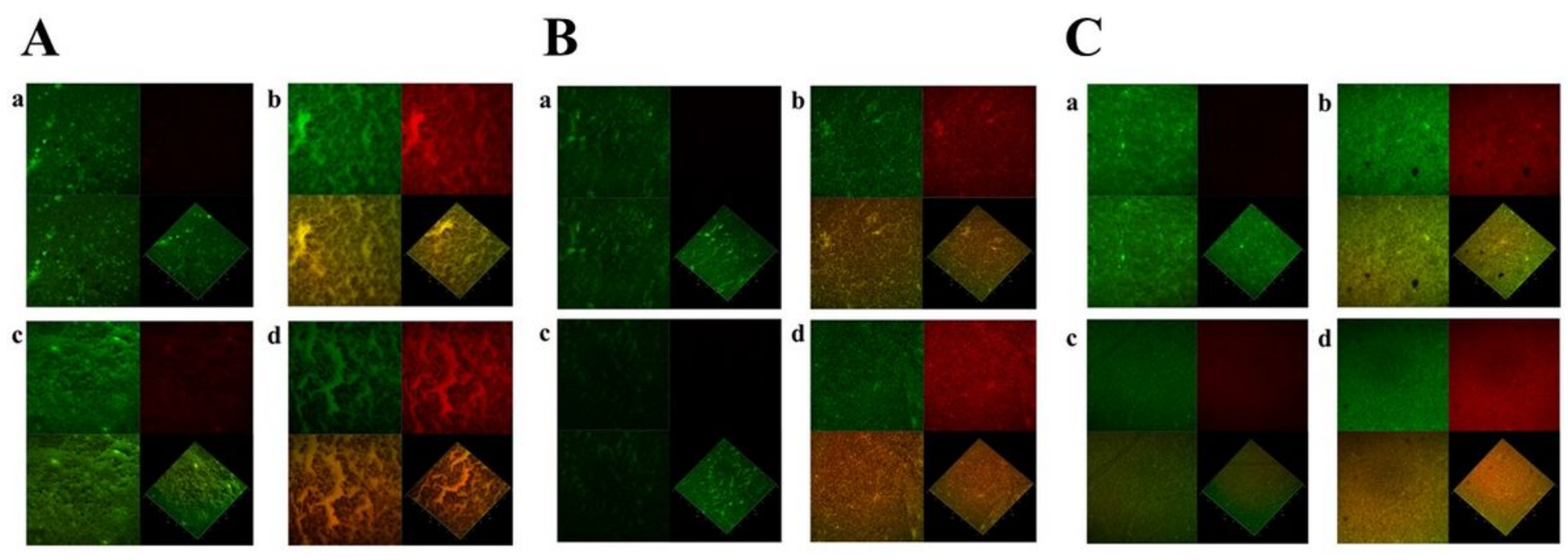

\section{Figure 4}

Effect of antibacterial combination on the on the viability of cultured biofilm. The confocal laser scanning microscope images of BacLight LIVE/DEAD stained biofilms of (A) Salmonella enterica serovar Typhimurium (ATCC14028) treated with [(a) no drug, (b) $1 \frac{1}{2} \mathrm{MIC}$ of gallic acid, (c) $1 \frac{1}{2} \mathrm{MIC}$ of ceftiofur, (d) $1 \frac{1}{2} \mathrm{MIC}$ of gallic acid and $1 \frac{1}{2} \mathrm{MIC}$ of ceftiofur], (B) Escherichia coli (ATCC25922) treated with [(a) no drug, (b) $1 \frac{1}{2} \mathrm{MIC}$ of hamamelitannin, (c) $1 \frac{1}{2} \mathrm{MIC}$ of erythromycin, (d) $\frac{1}{2} \mathrm{MIC}$ of hamamelitannin and $1 \frac{1}{2} \mathrm{MIC}$ of erythromycin], (C) Escherichia coli (ATCC25922) treated with [(a) no drug, (b) $1 \frac{1}{2} \mathrm{MIC}$ of gallic acid, (c) $1 \frac{1}{2} \mathrm{MIC}$ of ampicillin, (d) $1 \frac{1}{2} \mathrm{MIC}$ of gallic acid and $1 / 2 \mathrm{MIC}$ of ampicillin]. The viability of the biofilm cells were assessed using BacLight LIVE/DEAD stain (green: live cells, red: dead cells). In each image, the segment at below right side shows three dimensional and other three segments shows two dimensional images. 


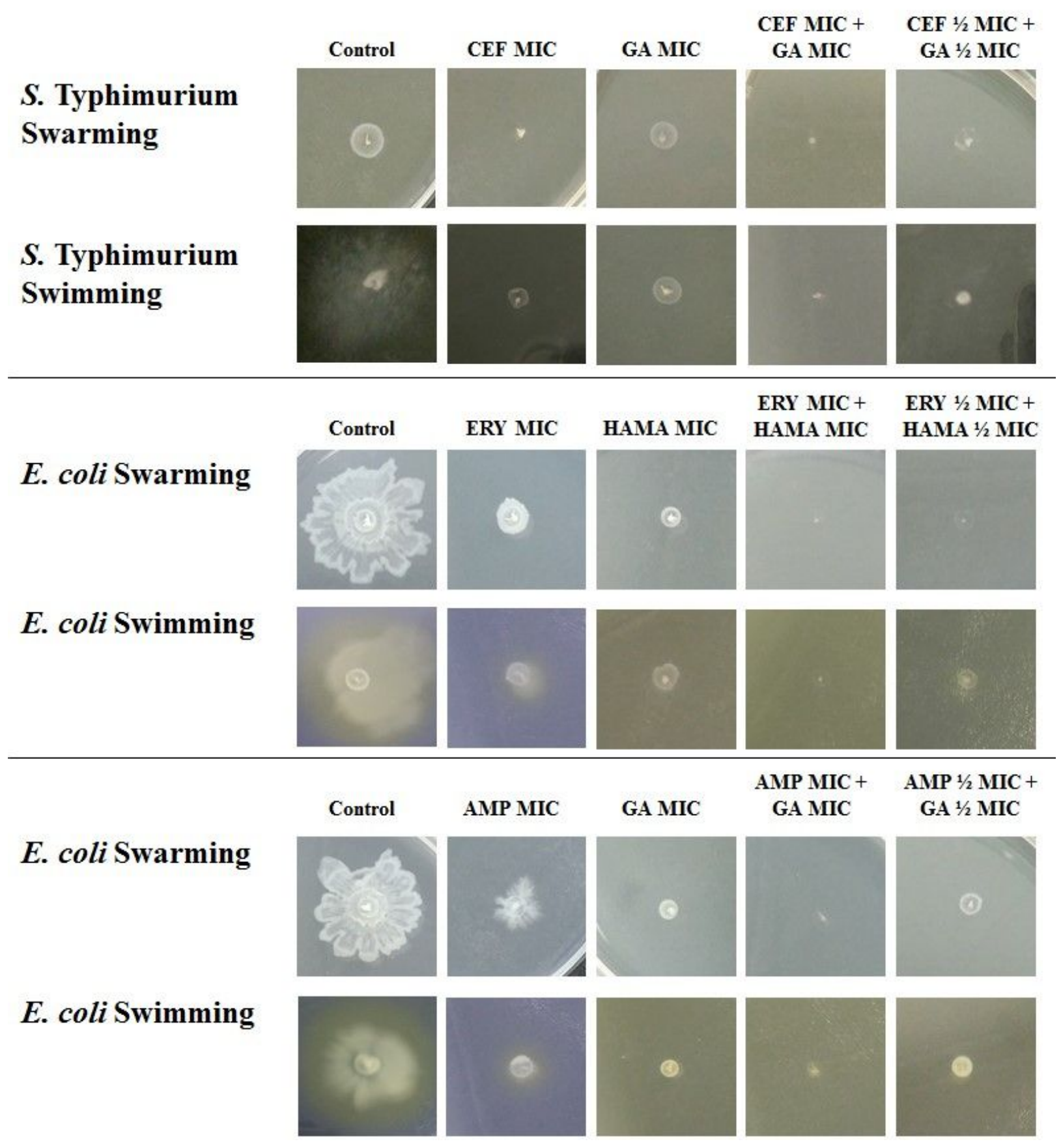

Figure 5

Representative images of swim and swarm zones of Salmonella enterica serovar Typhimurium (ATCC14028) treated with ceftiofur-gallic acid combination, and Escherichia coli (ATCC25922) treated with erythromycin-hamamelitannin and ampicillin-gallic acid combinations. CEF, ceftiofur; GA, gallic acid; ERY, erythromycin; HAMA, hamamelitannin; AMP, ampicillin; MIC: minimum inhibitory concentration. 
A

$\mathrm{IC}_{50}=564.55 \mu \mathrm{M}$

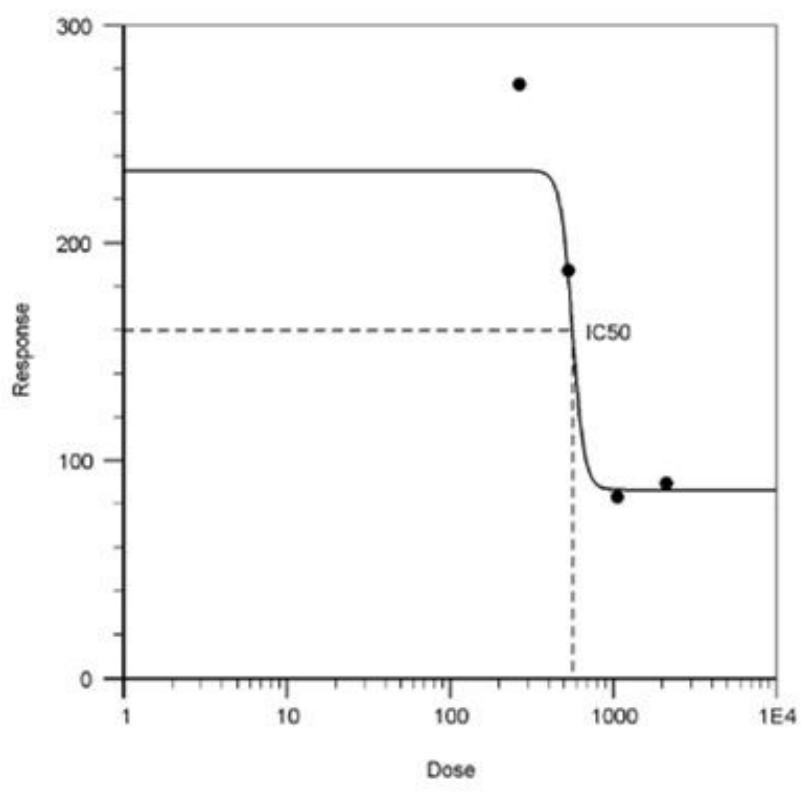

B

$\mathrm{IC}_{50}=988.54 \mu \mathrm{M}$

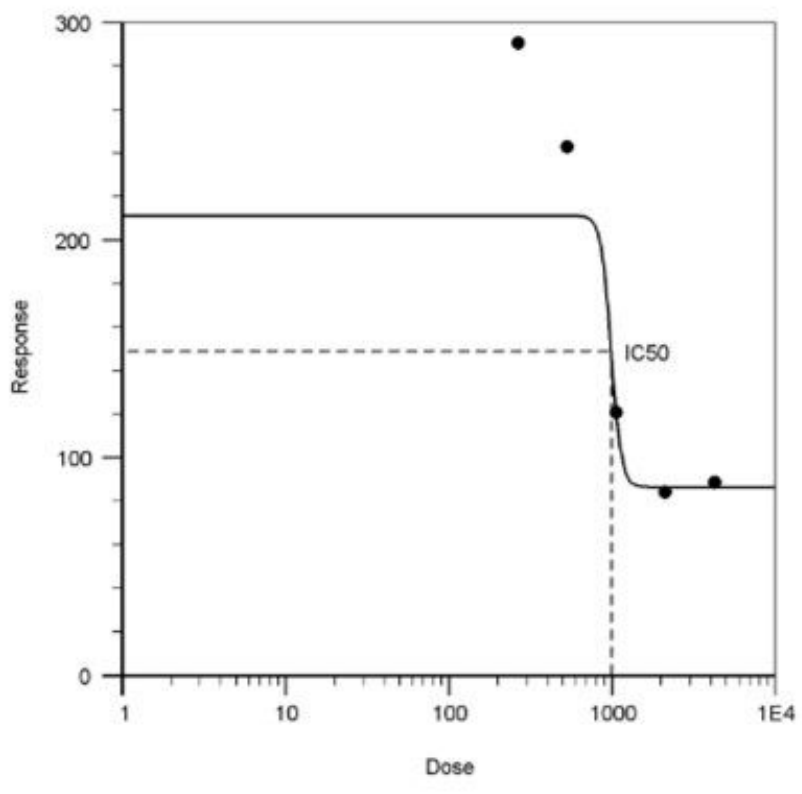

Figure 6

Effects of gallic acid and hamanelitannin on the viability of Rattus norvegicus (IEC-6) cell line. The dose-response curves of (A) gallic acid and (B) hamamelitannin.

\section{Supplementary Files}

This is a list of supplementary files associated with this preprint. Click to download.

- supplement1.docx

- supplement2.docx 